\title{
OBESIDADE: PODEMOS MELHORAR?
}

Obesidade é termo médico e também social. Classificar um indivíduo como obeso pode ser difícil, mas é certo que pode ocasionar agravos à saúde.

Esta doença vem merecendo atenção crescente como problema de saúde pública, em função do rápido aumento do número de pessoas obesas no mundo - segundo a Organização Mundial da Saúde, passou de 200 para 300 milhões de adultos entre 1995 e 2000 - e de suas conseqüências para os serviços de saúde. A OMS considerou recentemente a obesidade como uma epidemia global, afetando não só os países industrializados como também, e de forma crescente, aqueles em desenvolvimento sobrepondo-se ao problema da fome e da desnutrição.

Por que o mundo engorda? Serão os baixos gastos calóricos do nosso dia-a-dia ou será o consumo de alimentos de alto valor energético? São ambos! Do controle remoto ao telefone celular, passando pelo "home banking", pizzas "delivery", etc... gastam-se pouquíssimas calorias. Do "fast food" à "banana split", passando pelos "snack" e "drinks", consomem-se muitíssimas calorias. A conseqüência é a obesidade desenfreada, sem controle, epidêmica e de futuro pouco promissor. Ao querer esbanjar prosperidade, crescimento econômico e obesidade, paga-se um preço que também é pesado. De fato, a obesidade é uma condição de origem multifatorial, incluindose entre eles genéticos e ambientais; sócioculturais; endócrinos e neurológicos; emocionais e psicológicos.

Curiosamente, em nosso país, o desenvolvimento socioeconômico parece contri- buir para o controle da obesidade em contraste com o observado em outros países. De fato, a prevalência da obesidade em adultos só não está aumentando nas mulheres da região sudeste, pertencentes aos extrato de maior renda. Essa faixa de população dispõe de recursos culturais e econômicos que possibilitam a adoção de hábitos adequados, dietéticos e de atividade física.

$\mathrm{O}$ custo relacionado à obesidade pode ser estimado do ponto de vista econômico. O custo direto corresponde ao tratamento e de suas conseqüências incluindo consultas médicas, consumo de medicamentos, exames diagnósticos e internações hospitalares, assim como das doenças associadas, tais como hipertensão arterial, diabetes e arteriosclerose. Estima-se que este custo corresponda nos países industrializados de 2 a $8 \%$ do gasto total com saúde. 0 custo indireto está relacionado ao impacto sobre a qualidade de vida e a produtividade. A qualidade de vida é afetada em função do preconceito existente em relação aos obesos e também em função da dificuldade em desempenhar determinadas atividades e de encontrar emprego, entre outros. Embora seja difícil estimar com precisão o custo indireto, para a maioria das doenças em que foi estimado, foi muito superior ao custo direto.

A obesidade na infância é importante porque é uma possível preditora de sua ocorrência em idade adulta. Além disso, seus efeitos negativos persistem nas faixas etárias maiores. No município de São Paulo a freqüência de obesidade é relativamente baixa em crianças com variação discreta e não consistente entre os inquéritos realizados.
Porém, em países desenvolvidos, a prevalência da obesidade infantil é alta e vem aumentando progressivamente. Os avanços tecnológicos que, de um lado contribuem para facilitar a vida, por outro têm propiciado mudanças comportamentais e inovações constantes dentro do ambiente familiar. Assim, o uso crescente de alimentos industrializados com alto teor calórico, as propagandas de alimentos dos mais variados tipos em programas de televisão, principalmente infantis, são cada vez mais freqüentes e variados sendo, em geral, caracterizados por alimentos de baixa qualidade nutricional e de valor calórico elevado, proporcionando conflitos entre pais e filhos, visto que estes não sabem separar o que é mais conveniente para sua alimentação.

Entre as mulheres adultas, de 30\% a $40 \%$ são obesas, com índice de massa corpórea maior ou igual a 26 ou $27 \mathrm{~kg} / \mathrm{m} 2$. A obesidade associa-se freqüentemente a concentrações elevadas de estrogênio e testosterona, e as mulheres portadoras de síndrome dos ovários policísticos são um exemplo clássico dessa associação. O estado "hiperestrogênico" das obesas pode retardar a menopausa e aumenta o risco para doenças proliferativas como câncer de endométrio e de mama devido à exposição crônica ao esteróide endógeno. Desse modo, estas pacientes devem ser submetidas a avaliações mais freqüentes, e merecem cuidados no uso de medicações com ações símiles aos estrogênios como digitálicos, fenotiazínicos e ginseng. Além disso, na prescrição de terapia de reposição hormonal deve-se preferir as doses baixas de estrogênios. O sobrepeso pré-gravídico 
pode favorecer complicações durante a gravidez, como diabetes gestacional e distúrbios hipertensivos relacionados a alterações fetais como macrossomia e retardo do crescimento intra-uterino. Nas obesas, o pósoperatório das cesáreas mostra maior incidência de infecções, deiscências, hematomas, tromboflebites, etc.

A prevenção da obesidade ainda se constitui na melhor forma de tratamento, embora no mundo atual e para indivíduos geneticamente suscetíveis, não seja fácil praticá-la.

O tratamento para o obeso também mudou significantemente na última década. O objetivo terapêutico final é alcançar o peso saudável e não o peso ideal, o que, para muitos, significa uma perda em torno de 5 a 10\% do peso inicial. Todavia, essa perda nem sempre é conseguida quer com tratamento não-farmacológico quer com tratamento farmacológico.

O tratamento cirúrgico é recomendado para pacientes com obesidade mórbida, caracterizada pelo índice de massa maior ou igual a $40 \mathrm{~kg} / \mathrm{m}^{2}$. Contudo, também pode ser indicado em obesos com índices entre
35 e $40 \mathrm{~kg} / \mathrm{m}^{2}$, portadores de doenças crônicas agravadas pela obesidade. Os resultados da cirurgia dependem de seleção pré-operatória minuciosa com avaliação clínica e psicológica e de equipe altamente qualificada. $O$ esclarecimento prévio de riscos e benefícios, incluindo consentimento informado por escrito, pode evitar complicações psicológicas que podem culminar em tentativas de suicídio.

Os esforços no sentido de controlar a obesidade devem contar não somente com médicos, mas também com a sociedade em geral, incluindo as indústrias alimentícias e agências governamentais. Os preconceitos contra os obesos devem ser combatidos. Além disso, todos devem estar atentos contra a propaganda enganosa veiculada na imprensa médica com objetivos comerciais isolados ou na imprensa leiga ao divulgar tratamentos "milagrosos" como dietas, chás, aparelhos e procedimentos sem comprovação científica.

Em função do exposto, algumas medidas podem ser sugeridas: a) disseminação do conhecimento relativo às conseqüências e ao controle da obesidade, principal- mente para população de menor nível econômico; b) elaboração e adoção de uma pirâmide alimentar brasileira, de acordo com nossos padrões sócio-culturais e econômicos; c) redução do custo de alimentos com menor conteúdo calórico e/ou gorduroso; d) priorizar a construção de parques e centros esportivos públicos em bairros onde vive a população mais carente; e) monitorar a evolução dos indicadores de prevalência e controle da obesidade, considerando aspectos regionais, etários e socioeconômicos, a fim de avaliar, aprimorar e, eventualmente, substituir as intervenções implementadas f) introdução de uma boa prática dietética dentro do currículo escolar, a começar da merenda, freqüentemente baseada em opções não balanceadas e seguindo padrões norte-americano. Uma análise das conseqüências da obsesidade torna urgente a adoção destas medidas.

É óbvio que, embora seja difícil, devemos e podemos melhorar o controle da obesidade. É necessário definir estratégias e priorizar o direcionamento de recursos a fim de atingir os objetivos desejados. 